02

\title{
Кинетика сенсибилизированной люминесценции как инструмент для идентификации безызлучательного переноса энергии
}

\author{
(C) Е.Н. Бодунов \\ Петербургский государственный университет путей сообщения Императора Александра I, \\ 191031 Санкт-Петербург, Россия \\ e-mail: evgeny.bodunov@inbox.ru
}

Поступила в редакцию 14.10.2020 г.

В окончательной редакции 14.10.2020 г.

Принята к публикации 28.10.2020 г.

\begin{abstract}
Предложено простое уравнение для расчета кинетики сенсибилизированной люминесценции акцепторов, обусловленной безызлучательным переносом энергии (Förster Resonance Energy Transfer, FRET) электронного возбуждения от доноров. В уравнение в качестве параметров входят времена жизни возбужденных состояний донора и акцептора и экспериментальная кинетика затухания люминесценции доноров при наличии FRET. В уравнение не входит конкретный вид механизма FRET. Уравнение предлагается использовать для аппроксимации экспериментальной кинетики сенсибилизированной люминесценции с целью количественного подтверждения наличия FRET между донорами и акцепторами.
\end{abstract}

Ключевые слова: безызлучательный перенос энергии, сенсибилизированная люминесценция, кинетика затухания люминесценции.

DOI: $10.21883 /$ OS.2021.02.50554.262-20

\section{Введение}

Безызлучательный перенос энергии (Förster Resonance Energy Transfer, FRET) продолжает оставаться эффективным инструментом для исследования фотопроцессов в различных средах. В последние годы FRET используется в качестве инструмента для исследования нанокристаллов, квантовых точек (QD) и гибридных структур на их основе [1-16].

Доказательством существования FRET являются следующие его проявления [17-19]. Если FRET происходит между разными молекулами (или QD), то:

(1) при увеличении концентрации акцепторов энергии (молекул, QD) наблюдается уменьшение квантового выхода люминесценции доноров (молекул, QD), безызлучательно передающих энергию возбуждения акцепторам,

(2) кинетика затухания люминесценции доноров приобретает ферстеровский вид (stretched exponential, в общем случае $[8,20,21])$,

(3) появляется сенсибилизированная люминесценция (люминесценция акцепторов в отсутствие их прямого возбуждения) как результат FRET,

(4) наблюдается рост интенсивности сенсибилизированной люминесценции с увеличением концентрации акцепторов,

(5) на малых временах после импульсного возбуждения доноров наблюдается увеличение интенсивности сенсибилизированной люминесценции (enhancement of sensitized luminescence, ESL), а затем ее уменьшение [2].

Если FRET происходит между одинаковыми молекулами (или QD одного размера), то можно наблюдать:
(1) концентрационную деполяризацию люминесценции $[17,18,22,23]$,

(2) ферстеровскую (stretched exponential, в общем случаe) кинетику затухания анизотропии испускания люминесценции [24],

(3) сдвиг спектра люминесценции в длинноволновую сторону с увеличением концентрации молекул (или QD) при наличии неоднородного уширения спектров $[2,25,26]$,

(4) более быструю кинетику затухания люминесценции на коротковолновом краю неоднородно уширенного спектра по сравнению с кинетикой на длинноволновом краю, где возможно также ESL [2,25,26],

(5) эффект Вебера - исчезновение концентрационной деполяризации люминесценции у молекул в растворах при их возбуждении на длинноволновом краю неоднородно уширенного спектра поглощения $[27,28]$.

Заметим, что в большинстве работ наличие FRET подтверждается на количественном уровне совпадением экспериментальной кинетики затухания люминесценции доноров с кинетикой ферстеровского вида [17,18,29], а сенсибилизированная люминесценция акцепторов используется для доказательства FRET только на качественном уровне [2].

В настоящей работе выводится уравнение для кинетики сенсибилизированной люминесценции (молекул, QD) при произвольном механизме FRET. Она удобна для аппроксимации экспериментальной кинетики сенсибилизированной люминесценции и, следовательно, для подтверждения наличия FRET в исследуемой системе доноров и акцепторов. 

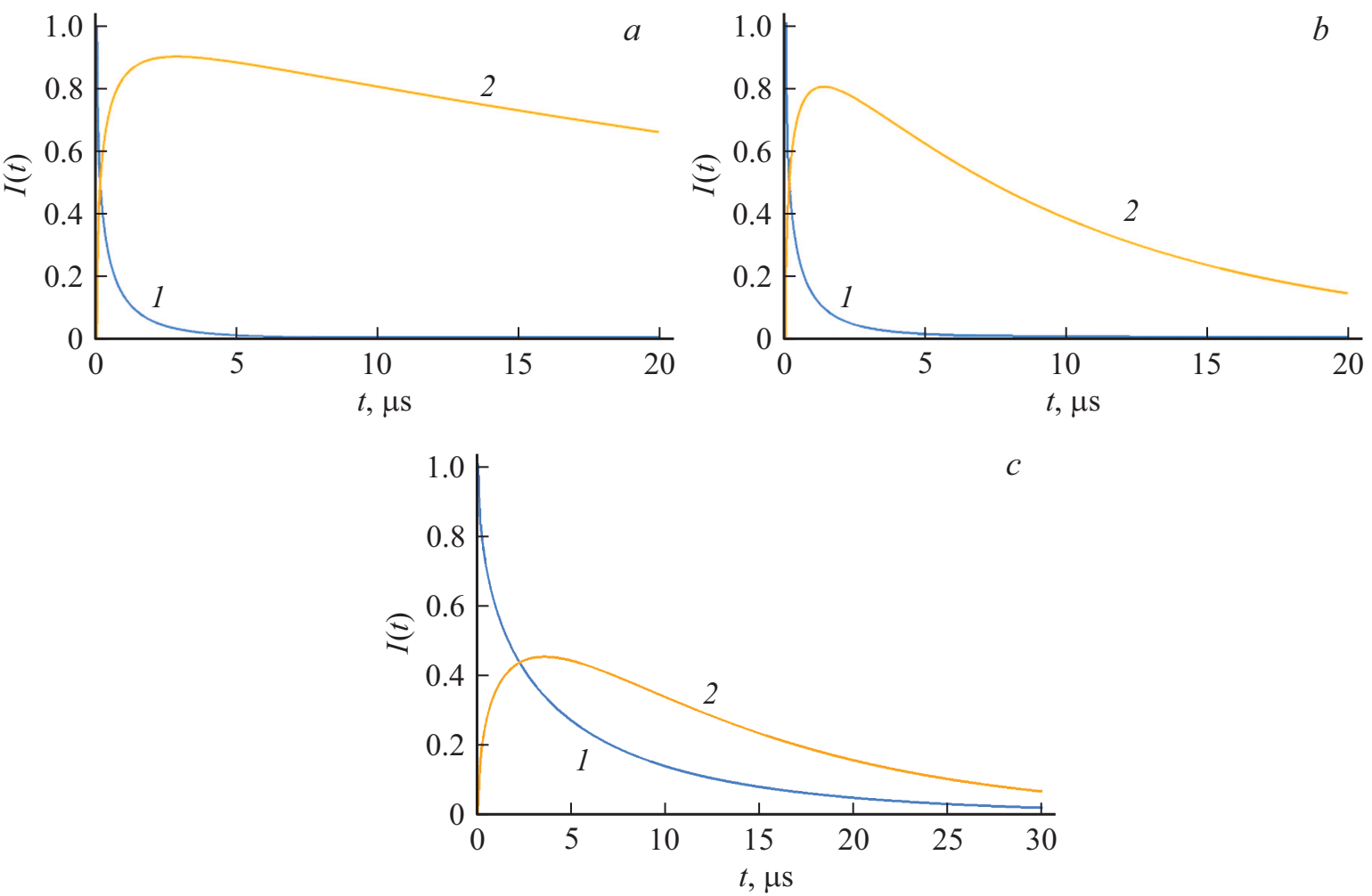

Рис. 1. Кинетика затухания люминесценции доноров (1) (синяя кривая, 1) и кинетика сенсибилизированной люминесценции акцепторов (9) (желтая кривая, 2) при диполь-дипольном механизме FRET и различных значениях параметров. $(a) \tau_{D}=25 \mu \mathrm{s}$, $\tau_{A}=50 \mu \mathrm{s}, a=2 \mu \mathrm{s}^{-1 / 2},(b) \tau_{D}=25 \mu \mathrm{s}, \tau_{A}=10 \mu \mathrm{s}, a=2 \mu \mathrm{s}^{-1 / 2}$, (c) $\tau_{D}=25 \mu \mathrm{s}, \tau_{A}=10 \mu \mathrm{s}, a=0.5 \mu \mathrm{s}^{-1 / 2}$.

\section{Уравнения}

Пусть после импульсного возбуждения интенсивность люминесценции доноров (нормированная на единицу в начальный момент времени) затухает согласно уравнению

$$
I_{D}(t)=e^{-\frac{t}{\tau_{D}}-k_{D}(t)} .
$$

В этом уравнении функция $k_{D}(t)$ определяется механизмом FRET от донора к акцептору; и мы предполагаем, что в отсутствие FRET $\left(k_{D}(t)=0\right)$ интенсивность люминесценции убывает экспоненциально со скоростью $1 / \tau_{D}$ $\left(\tau_{D}\right.$ - время жизни возбужденного состояния донора).

В случае диполь-дипольного механизма FRET в трехмерных средах $[17,18]$

$$
k_{D}(t)=a \sqrt{t} .
$$

Параметр $a$ определяется критическим радиусом FRET и концентрацией акцепторов. В средах другой размерности (например, фрактальных) зависимость $k_{D}(t)$ другая [30,31]:

$$
k_{D}(t)=a t^{d / s}
$$

и определяется размерностью среды $d$ и механизмом FRET $(s=6,8,10$ соответственно для дипольдипольного, диполь-квадрупольного и квадрупольквадрупольного механизмов). При обменном механизме переноса энергии [32] выражение для $k_{D}(t)$ более сложное $[17,18,33]$.

В случае контактного переноса энергии (осуществляемом только при непосредственном контакте донора и акцептора, т.е. при короткодействующем взаимодействии, обусловленном, например, малым критическим радиусом FRET или обменным взаимодействием донора и акцептора) [5,7,34-36]

$$
k_{D}(t)=\bar{N}(1-\exp (-k t))
$$

где $\bar{N}-$ среднее число акцепторов (ловушек) на доноpe (QD), $k$ - скорость переноса энергии с донора на один акцептор (ловушку).

Из уравнения (1) для кинетики люминесценции получаем следующее дифференциальное уравнение:

$$
\frac{d I_{D}}{d t}=-\frac{1}{\tau_{D}} I_{D}-\frac{d k_{D}}{d t} I_{D}
$$

Первое слагаемое в правой части формулы (5) обусловлено излучательными и безызлучательными переходами в самом доноре со скоростью $1 / \tau_{D}$. Во втором слагаемом множитель $d k_{D} / d t$ имеет смысл скорости передачи энергии возбуждения от донора к акцепторам.

Будем далее предполагать, что люминесценция акцепторов при их прямом импульсном возбуждении также 

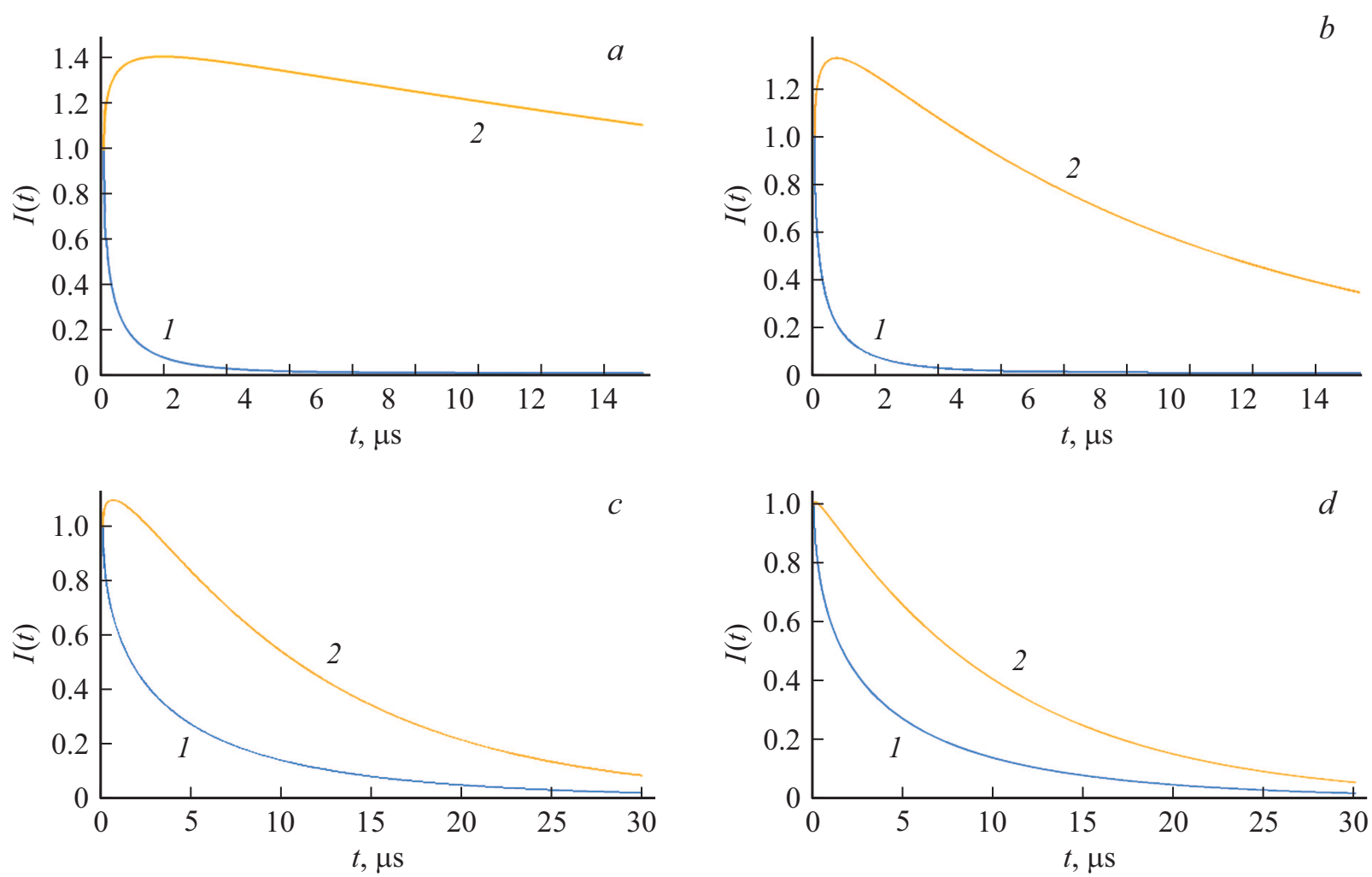

Рис. 2. Кинетика затухания люминесценции доноров (1) (синяя кривая, 1) и кинетика сенсибилизированной люминесценции (13) (желтая кривая, 2) при диполь-дипольном механизме FRET (2). В начальный момент времени возбуждены доноры и акцепторы $(D / A=0.5-a-c, D / A=0.1-d)$. Значения параметров: $(a) \tau_{D}=25 \mu \mathrm{s}, \tau_{A}=50 \mu \mathrm{s}, a=2 \mu \mathrm{s}^{-1 / 2},(b) \tau_{D}=25 \mu \mathrm{s}, \tau_{A}=10 \mu \mathrm{s}$, $a=2 \mu \mathrm{s}^{-1 / 2},(c, d) \tau_{D}=25 \mu \mathrm{s}, \tau_{A}=10 \mu \mathrm{s}, a=0.5 \mu \mathrm{s}^{-1 / 2}$. Участок ESL практически исчезает при увеличении доли акцепторов, возбужденных в начальный момент времени (рис. $c$ и $d$ ).

затухает экспоненциально со скоростью $1 / \tau_{A}\left(\tau_{A}-\right.$ время жизни возбужденного состояния акцептора). Тогда кинетика сенсибилизированной люминесценции акцепторов (в соответствии с уравнением (5)) подчиняется уравнению

$$
\frac{d I_{A}}{d t}=-\frac{1}{\tau_{A}} I_{A}+\frac{d k_{D}(t)}{d t} I_{D}
$$

Второе слагаемое в правой части этой формулы (в соответствии с предыдущей интерпретацией уравнения (5)) описывает возбуждение акцепторов за счет FRET со скоростью $d k_{D} / d t$.

Уравнение (6) решаем при начальных условиях

$$
I_{D}(0)=1, I_{A}(0)=0,
$$

т. е. полагаем, что в начальный момент времени возбуждены только доноры, а акцепторы находятся в основном состоянии.

Решение уравнения (6) с учетом (1) и (7) имеет вид

$$
I_{A}(t)=e^{-t / \tau_{A}} \int_{0}^{t} e^{t^{\prime} / \tau_{A}} \frac{d k_{D}\left(t^{\prime}\right)}{d t^{\prime}} I_{D}\left(t^{\prime}\right) d t^{\prime} .
$$

После интегрирования выражения (8) по частям получаeм

$$
\begin{aligned}
I_{A}(t) & =e^{-t / \tau_{A}}-I_{D}(t)+\left(\frac{1}{\tau_{A}}-\frac{1}{\tau_{D}}\right) e^{-t / \tau_{A}} \\
& \times \int_{0}^{t} e^{t^{\prime} / \tau_{A}} I_{D}\left(t^{\prime}\right) d t^{\prime} .
\end{aligned}
$$

Кинетика затухания люминесценции доноров (1) и кинетика сенсибилизированной люминесценции акцепторов (9) при диполь-дипольном механизме FRET (2) представлены на рис. 1. На начальных временах наблюдается ESL. На больших временах люминесценция акцепторов затухает экспоненциально со скоростью $1 / \tau_{A}$.

Заметим, что в уравнении (9) не конкретизируется вид функции $I_{D}(t)$ (т.е. механизм переноса энергии, $\left.k_{D}(t)\right)$. Поэтому в уравнение $(9)$ в качестве $I_{D}(t)$ (нормированной кинетики затухания люминесценции доноров) может использоваться экспериментально измеренная кинетика. Последняя может быть аппроксимирована, например, суммой трех экспонент:

$$
I_{D}(t)=A_{1} e^{-t / \tau_{1}}+A_{2} e^{-t / \tau_{2}}+A_{3} e^{-t / \tau_{3}},
$$



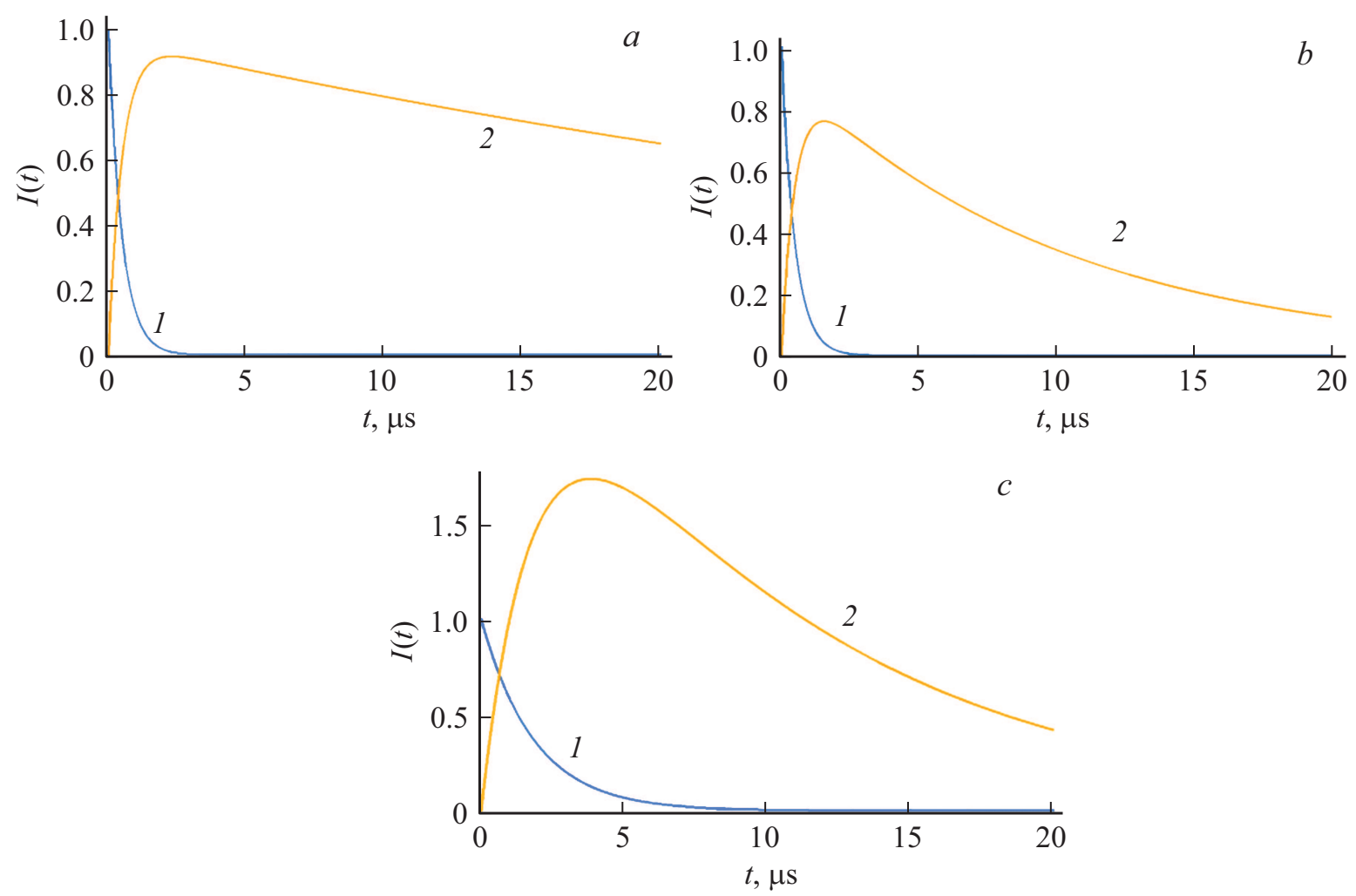

Рис. 3. Кинетика затухания люминесценции доноров (1) при $k_{D}(t)=k t$ (синяя кривая, 1 ) и кинетика сенсибилизированной люминесценции (14) (желтая кривая, 2) при различных значениях параметров. (a) $\tau_{D}=25 \mu \mathrm{s}, \tau_{A}=50 \mu \mathrm{s}, k=2 \mu \mathrm{s}^{-1}$, (b) $\tau_{D}=25 \mu \mathrm{s}$, $\tau_{A}=10 \mathrm{~s}, k=2 \mu \mathrm{s}^{-1},(c) \tau_{D}=25 \mu \mathrm{s}, \tau_{A}=10 \mu \mathrm{s}, k=0.5 \mu \mathrm{s}^{-1}$.

где коэффициенты $A_{i}\left(A_{1}+A_{2}+A_{3}=1\right)$ и времена $\tau_{i}-$ параметры аппроксимации. Подставляя экспериментальную кинетику (10) в уравнение (9), рассчитываем кинетику сенсибилизированной люминесценции $I_{A}(t)$. При ее совпадении с экспериментальной кинетикой сенсибилизированной люминесценции, $I_{\exp A}(t)$, можно делать обоснованный вывод о наличии FRET между донорами и акцепторами.

Подгоночным параметром в такой процедуре аппроксимации экспериментальной кинетики сенсибилизированной люминесценции $I_{\text {ехрА }}(t)$ является единственная константа $b$ (пропорциональная скорости радиационного затухания акцептора): $I_{\exp A}(t)=b I_{A}(t)$. Остальные параметры, входящие в $(9)\left(\tau_{A}, \tau_{D}\right.$ и $\left.I_{D}(t)\right)$, могут быть найдены из независимых экспериментов.

Если в начальный момент времени возбуждены и доноры, и акцепторы, то уравнение (6) следует решать при начальных условиях

$$
I_{D}(0)=D, I_{A}(0)=A
$$

Здесь параметры $D$ и $A$ характеризуют степень начального возбуждения доноров и акцепторов соответственно.
При начальных условиях (11) решение уравнения (6) приобретает вид

$$
\begin{aligned}
I_{A}(t) & =A e^{-t / \tau_{A}}+D\left(e^{-t / \tau_{A}}-I_{D}(t)+\left(\frac{1}{\tau_{A}}-\frac{1}{\tau_{D}}\right)\right. \\
& \left.\times e^{-\frac{t}{\tau_{A}}} \int_{0}^{t} e^{t^{\prime} / \tau_{A}} I_{D}\left(t^{\prime}\right) d t^{\prime}\right),
\end{aligned}
$$

где первое слагаемое описывает люминесценцию акцепторов, возбужденных непосредственно в начальный момент времени, а второе - сенсибилизированную люминесценцию.

Нормируя кинетику (12) в начальный момент времени на единицу $\left(I_{A}(0)=1\right)$, получаем

$$
\begin{aligned}
I_{A}(t) & =e^{-t / \tau_{A}}+\frac{D}{A}\left(e^{-t / \tau_{A}}-I_{D}(t)+\left(\frac{1}{\tau_{A}}-\frac{1}{\tau_{D}}\right) e^{-\frac{t}{\tau_{A}}}\right. \\
& \left.\times \int_{0}^{t} e^{t^{\prime} / \tau_{A}} I_{D}\left(t^{\prime}\right) d t^{\prime}\right),
\end{aligned}
$$

Кинетика сенсибилизированной люминесценции акцепторов, рассчитанная по формуле (13), при отличном от нуля начальном возбуждении акцепторов $(D / A=0.5)$ 

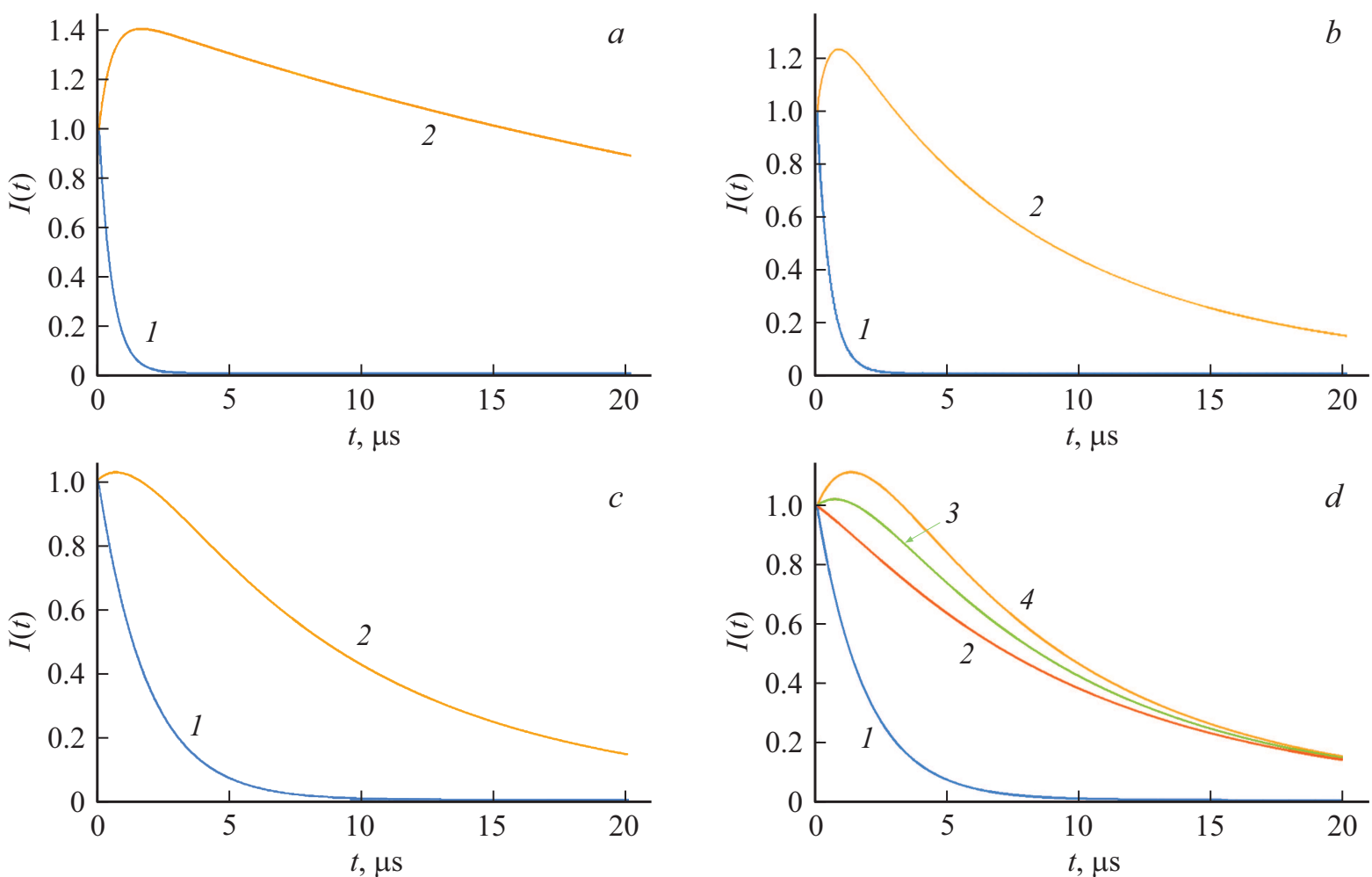

Рис. 4. Кинетика затухания люминесценции доноров $(1)$ при $k_{D}(t)=k t$ (нижняя, синяя кривая, 1$)$ и кинетика сенсибилизированной люминесценции (15) (желтая кривая, 2). В начальный момент времени возбуждены доноры и акцепторы. $D / A=0.5(a, b, c)$, 0.1 (красная, 2), 0.5 (зеленая, 3) и 0.9 (желтая, 4) (d). Значения параметров: (a) $\tau_{D}=25 \mu \mathrm{s}, \tau_{A}=50 \mu \mathrm{s}, k=2 \mu \mathrm{s}^{-1},(b) \tau_{D}=25 \mu \mathrm{s}$, $\tau_{A}=10 \mu \mathrm{s}, k=2 \mu \mathrm{s}^{-1},(c, d) \tau_{D}=25 \mu \mathrm{s}, \tau_{A}=10 \mu \mathrm{s}, k=0.5 \mu \mathrm{s}^{-1}$. Участок ESL исчезает при увеличении доли акцепторов, возбужденных в начальный момент времени (рис. $d$ ).

представлена на рис. 2. На начальном промежутке времени наблюдается ESL. Однако с увеличением доли возбужденных акцепторов (т. е. при уменьшении отношения $D / A)$ время ESL сокращается, и даже ESL практически не наблюдается (рис. $2, d$ ). В этих условиях основной вклад в люминесценцию акцепторов дают те акцепторы, которые были возбуждены в начальный момент времени.

Уравнение (13) можно использовать для аппроксимации экспериментальной кинетики сенсибилизированной люминесценции, $I_{\text {ехрА }}(t)$. Если известны времена жизни $\tau_{A}, \tau_{D}$ и нормированная кинетика затухания люминесценции доноров $I_{D}(t)\left(I_{D}(0)=1\right)$, то единственным подгоночным параметром является отношение $D / A-$ параметр, равный отношению количества возбужденных доноров к количеству возбужденных акцепторов в начальный момент времени.

Рассмотрим упрощенный случай, когда $k_{D}(t)=k t$, т.е. скорость переноса энергии $(k)$ не зависит от времени. Тогда из (9) получаем

$$
\begin{aligned}
I_{A}(t) & =\frac{k}{1 / \tau_{D}-1 / \tau_{A}+k} \\
& \times e^{-t / \tau_{A}\left(1-e^{-\left(1 / \tau_{D}-1 / \tau_{A}+k\right) t}\right)} .
\end{aligned}
$$

Кинетики затухания люминесценции доноров и соответствующие им кинетики сенсибилизированной люминесценции (14) при различных значениях параметров изображены на рис. 3.

Если учесть, что одновременно возбуждаются доноры и акцепторы, то из $(13)$ при $k_{D}(t)=k t$ получаем

$$
\begin{aligned}
I_{A}(t) & =e^{-t / \tau_{A}}\left[1+\frac{D}{A} \frac{k}{1 / \tau_{D}-1 / \tau_{A}+k}\right. \\
& \left.\times\left(1-e^{-\left(1 / \tau_{D}-1 / \tau_{A}+k\right) t}\right)\right] .
\end{aligned}
$$

Кинетики затухания люминесценции доноров и соответствующие им кинетики сенсибилизированной люминесценции акцепторов (15) при различных значениях параметров изображены на рис. 4. С увеличением степени возбуждения акцепторов (с уменьшением $D / A$ от 0.5 до 0.1 , рис. $4, c$ и $4, d$ ) участок ESL практически исчезает.

Уравнение (15) использовалось для аппроксимации экспериментальных данных в работе [15].

Обращает внимание качественная схожесть кривых, представленных на рис. 1, 3 и рис. 2,4. Конечно, существует количественное различие в их временном поведении, что иллюстрирует рис. 5, на котором сравниваются кинетики сенсибилизированной люминесценции (9) 


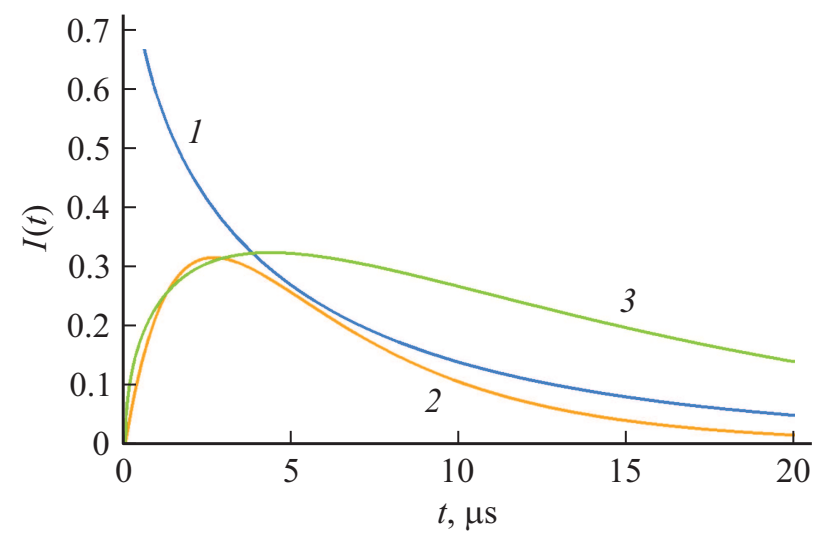

Рис. 5. Кинетика затухания люминесценции доноров (1) (синяя кривая, 1), кинетика сенсибилизированной люминесценци (9) (желтая кривая, 2) при диполь-дипольном механизме FRET и упрощенная кинетика (14) (зеленая, 3). Значения параметров: $\tau_{D}=25 \mu \mathrm{s}, \tau_{A}=10 \mu \mathrm{s}, a=0.3 \mu \mathrm{s}^{-1 / 2}, k=0.5 \mu \mathrm{s}^{-1}$.

и (14). На начальном временном участке $(t<3 \mu \mathrm{s})$ кинетики (9) и (14) различаются мало (при выбранных значениях параметров). Значительное различие наблюдается на больших временах.

Отметим, что процесс сенсибилизированной люминесценции в некоторых чертах похож на процесс замедленной люминесценции (delay luminescence), в котором триплетные состояния молекул играют роль доноров энергии возбуждения для синглетных состояний. Как отмечается в работе [37], замедленная люминесценция наблюдается в QD при обратимом захвате носителей заряда ловушками [38,39]. Уравнения, описывающие кинетику затухания люминесценции QD в этом случае, были представлены в работах $[38,39]$ и использовались для анализа кинетики люминесценции коллоидных $\mathrm{CdSe} / \mathrm{ZnS}$ $\mathrm{QD}$ и гибридных наноструктур InP/InAsP/InP [16].

\section{Выводы}

Получены простые уравнения (9) и (13), описывающее кинетику сенсибилизированной люминесценции акцепторов. В этих уравнениях не конкретизируется механизм FRET. Параметрами уравнений (9) и (13) являются (i) время жизни возбужденного состояния акцептора $\tau_{A}$, (ii) время жизни возбужденного состояния донора $\tau_{D}$, (iii) нормированная кинетика затухания люминесценции доноров $I_{D}(t)$, (iv) параметр $b$ (когда функция (9) используется для аппроксимации экспериментальной кинетики сенсибилизированной люминесценции $\left.I_{\exp A}(t), I_{\exp A}(t)=b I_{A}(t)\right)$ или отношение количества возбужденных доноров $D$ к количеству возбужденных акцепторов $A$ в начальный момент времени, $D / A$ (когда функция (13) используется для аппроксимации $I_{\exp A}(t)$; в этом случае $I_{\exp A}(t)$ нормируется на единицу: $\left.I_{\exp A}(0)=1\right)$. Поскольку первые три параметра $\left(\tau_{A}, \tau_{D}\right.$ и $\left.I_{D}(t)\right)$ можно определить из независимых экспериментов, то $b$ и $D / A-$ единственные подгоночные параметры при аппроксимации экспериментальной кинетики сенсибилизированной люминесценции $I_{\exp A}(t)$ соответственно функциями (9) или (13).

Уравнения (9) и (13) могут предоставить дополнительные количественные доказательства наличия FRET в системе доноров и акцепторов.

\section{Список литературы}

[1] Kagan C.R., Murray C.B., Bawend M.G. // Phys. Rev. B. 1996. V. 54. P. 8633. doi 10.1103/PhysRevB.54.8633

[2] Klimov V.I. // J. Phys. Chem. B. 2003. V. 107. P. 13782. doi $10.1021 / \mathrm{jp} 036497 \mathrm{r}$

[3] Guyot-Sionnest P., Wehrenberg B., Yu D. // J. Chem. Phys. 2005. V. 123. P. 074709. doi $10.1063 / 1.2004818$

[4] Zenkevich E., Cichos F., Shulga A., Petrov E.P., Blaudeck T., von Borczyskowski C. // J. Phys. Chem. B. 2005. V. 109. N 18. P. 8679. doi 10.1021/jp040595a

[5] Koole R., Luigjes B., Tachiya M., Pool R., Vlugt T.J.H., de Mello Donegá C., Meijerink A., Vanmaekelbergh D. // J. Phys. Chem. C. 2007. V. 111. P. 11208. doi 10.1021/jp072407x

[6] Aharoni A., Oron D., Banin U., Rabani E., Jortner J. // Phys. Rev. Lett. 2008. V. 100. P. 057404. doi 10.1103/PhysRevLett.100.057404

[7] Sadhu S., Tachiya M., Patra A. // J. Phys. Chem. C. 2009. V. 113 (45). P. 19488. doi 10.1021/jp906160z

[8] Stewart M.H., Huston A.L., Scott A.M., Efros Al.L., Melinger J.S., Boeneman Gemmill K., Trammell S.A., BlancoCanosa J.B., Dawson P.E., Medintz I.L. // ACS Nano. 2012. V. 6. P. 5330.

[9] Orlova A.O., Kurochkina M.A., Gromova Y.A., Maslov V.G., Bodunov E.N., Baranov A.V., Fedorov A.V. // Proc. SPIE 9126. Nanophotonics. V. 912617 (2 May 2014). doi 10.1117/12.2052170

[10] Keuleyan S., Kohler J., Guyot-Sionnest P. // J. Phys. Chem. C. 2014. V. 118. P. 2749. doi 10.1021/jp409061g

[11] Preeyanka N., Dey H., Seth S., Rahaman A., Sarkar M. // Phys. Chem. Chem. Phys. 2020. V. 22. P. 12772. doi 10.1039/D0CP01845G

[12] Bodunov E.N., Danilov V.V., Panfutova A.S., Simões Gamboa A.L. // Ann. Phys. (Berlin) 2016. V. 528. P. 272. doi 10.1002/andp.201500350

[13] Popov A.V., Vanetsev A.S., Keevend K., Kaldvee K., Puust L., Baranchikov A.E., Ryabova A.V., Fedorenko S.G., Kiisk V., Sildos I., Kikas J., Steiner R., Loschenov V.B., Orlovskii Yu.V. // J. Luminescence. 2016. V. 169. Part B. P. 722. doi 10.1016/j.jlumin.2015.03.015

[14] Stroyuk O., Raevskaya A., Spranger F., Gaponik N., Zahn D.R.T. // ChemPhysChem. 2019. V. 20(12). P. 1640-1648. doi 10.1002/cphc.201900088

[15] Кулагина А.С., Хребтов А.И., Резник Р.Р., Убыйвовк Е.В., Литвин А.П., Скурлов И.Д., Цырли Г.Э., Бодунов Е.Н., Данилов В.В. // Опт. и спектр. 2020. Т. 128. № 1. C. 122-127; Kulagina A.S., Khrebtov A.I., Reznik R.R., Ubyivovk E.V., Litvin A.P., Skurlov I.D., Cirlin G.E., Bodunov E.N., Danilov V.V. // Opt. Spectrosc. 2020. V. 128. N 1. P. 119. doi 10.1134/S0030400X20010129 
[16] Хребтов А.И., Кулагина А.С., Данилов В.В., Громова Е.С., Скурлов И.Д., Литвин А.П., Резник Р.Р., Штром И.В., Цырлин Г.Э. // ФТП. 2020. Т. 54. B. 9. C. 952. doi 10.21883/FTP.2020.09.49838.32; Khrebtov AI., Kulagina AS., Danilov V.V., Gromova E.S., Skurlov I.D., Litvin A.P., Reznik R.R., Shtrom I.V., Girlin G.E. // Semiconductors. 2020. V. 54. P. 1141. doi $10.1134 / \mathrm{S} 1063782620090158$

[17] Ермолаев В.Л., Бодунов Е.Н., Свешникова Е.Б., Шахвердов T.A. Безызлучательный перенос энергии электронного возбуждения. Л.: Наука, 1977. [Электронный pecypc] Режим доступа: https://www.researchgate.net/ publication/285333876_Radiationless_Transfer_of_

Electronic_Excitation_Energy; Ermolaev V.L., Bodunov E.N., Sveshnikova E.B., Shakhverdov T.A. Radiationless Transfer of Electronic Excitation Energy. Leningrad: Nauka, 1977. [Электронный ресурс] Режим доступа: https://www.researchgate.net/publication/285333876

_Radiationless_Transfer_of_Electronic_Excitation_Energy

[18] Valeur B., Berberan-Santos M.N. Molecular Fluorescence: Principles and Applications. 2012.

[19] Ermolaev V.L., Sveshnikova E.B., Bodunov E.N. // Phys.-Usp. 1996. V. 39. P. 261. doi 10.1070/PU1996v039n03ABEH000137

[20] Berberan-Santos M.N., Bodunov E.N., Valeur B. // Chem. Phys. 2005. V. 315. P. 171. doi 10.1016/j.chemphys.2005.04.006

[21] Берберан-Сантос М.Н., Бодунов Е.Н., Мартиню Ж.М.Г. // Опт. и спектр. 1999. Т. 87. № 1. С. 74; Berberan-Santos M.N., Bodunov E.N., Martinho J.M.G. // Opt. Spectrosc. 1999. V. 87. N 1. P. 66.

[22] Бодунов Е.Н. // Орт. и спектр. 1993. Т. 74. № 3. С. 518; Bodunov E.N. // Opt. Spectrosc. 1993. V. 74. N 3. P. 311.

[23] Bodunov E.N. // J. App. Spectrosc. 1977. V. 26(6). P. 814. doi 10.1007/BF01124496

[24] Bodunov E.N., Berberan-Santos M.N. // Opt. Spectrosc. 2015. V. 119. P. 22. doi 10.1134/S0030400X1507005X

[25] Bodunov E.N., Malyshev V.A. // J. App. Spectrosc. 1984. V. 41 (4). P. 1123. doi 10.1007/BF00659500

[26] Бодунов Е.Н. // Опт. и спектр. 1998. Т. 84. № 3. С. 405; Bodunov E.N. // Opt. Spectrosc. 1998. V. 84. N 3. P. 350.

[27] Weber G., Shinitzky M. // Proc. Nat. Acad. Sci. USA. 1970. V. 65. P. 823 .

[28] Бодунов Е.Н., Колобкова Е.В., Ермолаев В.Л. // Опт. и спектр. 1978. Т. 44. № 2. С. 252; Bodunov E.N., Kolobkova E.V., Ermolaev V.L. // Opt. Spectrosc. 1978. V. 44. N 2. P. 146.

[29] Popov A.V., Fedorenko S.G., Krut'ko V.A., Iskhakova L.D., Komova M.G., Timofeeva E.E., Kononkova N.N., Orlovskii Yu.V. // J. Alloys and Compounds. 2020. V. 822. P. 153654. doi 10.1016/j.jallcom.2020.153654

[30] Klafter J., Blumen A. // J. Chem. Phys. 1984. V. 80. P. 875. doi $10.1063 / 1.446743$

[31] Берберан-Сантуш М.Н., Бодунов Е.Н., Мартиню Ж.М.Г. // Опт. и спектр. 1996. Т. 81. № 2. С. 243; Berberan-Santos M.N., Bodunov E.N., Martinho J.M.G. // Opt. Spectrosc. 1996. V. 81. N 2. P. 217.

[32] Dexter D.L. // J. Chem. Phys. 1953. V. 21. P. 836. doi 10.1063/1.1699044

[33] Berberan-Santos M.N., Bodunov E.N. // Opt. Spectrosc. 2004. V. 97. N 3. P. 375. doi 10.1134/1.1803641
[34] Bodunov E.N., Simões Gamboa A.L. // J. Phys. Chem. C. 2018. V. 122. P. 10637. doi 10.1021/acs.jpcc.8b02779

[35] Bodunov E.N., Antonov Yu.A., Simões Gamboa A.L. // J. Chem. Phys. 2017. V. 146. P. 114102. doi 10.1063/1.4978396

[36] Bodunov E.N., Simões Gamboa A.L. // Semiconductors. 2018. V. 52. N 5. P. 587. doi 10.1134/S1063782618050044

[37] Ермолаев В.Л. // Опт. и спектр. 2018. Т. 125. № 2. С. 247; Ermolaev V.L. // Opt. Spectrosc. 2018. V. 125. P. 256. doi 10.1134/S0030400X18080052

[38] Bodunov E.N., Simões Gamboa A.L. // Semiconductors. 2019. V. 53. N 16. P. 2133. doi 10.1134/S1063782619120078

[39] Bodunov E.N., Simões Gamboa A.L. // J. Phys. Chem. C. 2019. V. 123. P. 25515. doi 10.1021/acs.jpcc.9b07619 